\title{
Efficacy and safety of laparoendoscopic single-site adrenalectomy versus conventional laparoscopic adrenalectomy: an updated systematic review and meta-analysis
}

\author{
Jianghua Jia, Zhan Yang, Zhihai Teng, Zhenwei Han \\ Department of Urology, The Second Hospital of Hebei Medical University, Hebei, China
}

Videosurgery Miniinv 2022; 17 (1): 20-34 DOI: https://doi.org/10.5114/wiitm.2021.110446

\begin{abstract}
Introduction: Laparoendoscopic single-site adrenalectomy (LESSA) has the advantages of early recovery and better cosmetic appearance. However, there are still debates on the efficacy and safety of LESSA and conventional laparoscopic adrenalectomy (CLA).

Aim: To reevaluate the efficacy and safety of LESSA vs CLA for adrenal lesions.

Material and methods: A systematic literature research of PubMed, Ovid, Scopus (up to February 2021), and citation lists was performed to identify eligible studies. All studies comparing LESSA versus CLA were included. Data were analyzed using the RevMan 5.4 software.

Results: Overall, eighteen studies including 1307 patients (LESSA 520; CLA 787) were included. LESSA was associated with smaller mean tumor size (weighted mean difference $(W M D)=0.53 \mathrm{~cm}, 95 \% \mathrm{Cl}:-0.81$ to $-0.24 ; p<0.001$ ). The operative time for LESSA was longer than CLA (WMD = $13.86 \mathrm{~min}, 95 \% \mathrm{Cl}: 4.43$ to 23.30; $p=0.004)$. LESSA had a better visual analog scale (VAS) score (WMD $=-0.56,95 \% \mathrm{Cl}:-1.01$ to $-0.11 ; p=0.02)$, shorter return to diet time $(W M D=-0.27$ days, $95 \% \mathrm{Cl}:-0.52$ to $-0.03 ; p=0.03)$, shorter length of hospital stay $(W M D=-0.56$ days, $95 \% \mathrm{Cl}$ : -1.01 to $-0.11 ; p=0.01$ ), and comparable postoperative complications (OR=0.98, 95\% Cl: 0.56 to $1.70 ; p=0.93$ ). The wound size of LESSA was definitely smaller (WMD $=-2.72 \mathrm{~cm}, 95 \% \mathrm{Cl}:-3.50$ to $-1.94 ; p<0.001)$. The subgroup analysis of studies via the transperitoneal approach showed reasonable results.

Conclusions: LESSA is significantly better in terms of postoperative pain, time to diet, length of hospital stay and wound size, but the operative time is significantly longer.
\end{abstract}

Key words: adrenalectomy, meta-analysis, laparoendoscopic single-site, laparoscopic.

\section{Introduction}

Laparoscopic adrenalectomy has the advantages of better pain control, cosmetic appearance, decreased complications, shortened length of hospital stay, and lower costs. Therefore, it is still the gold standard surgical treatment for small adrenal tumors. However, conventional laparoscopic adrenalectomy (CLA) requires three to five access ports, depending on the complexity of the procedure [1].
CLA will cause three to five permanent scars, affecting cosmetic appearance. Scarless surgery is always a worthwhile goal. With the development of technological instruments and surgical skills, minimally invasive surgery has been improving. Laparoendoscopic single-site adrenalectomy (LESSA) is a scar-free or short-scar procedure, which has the advantages of early recovery and better cosmetic appearance [2]. However, this procedure 
requires surgeons to manipulate various instruments through a small incision, which makes the operation more difficult and prolongs the learning curve. Moreover, the use of special equipment increases the cost of surgery $[3,4]$. Due to the steep learning curve and increased cost-effectiveness, the efficacy and safety of this procedure have been controversial.

Previous meta-analyses comparing LESSA and CLA have not shown consistent results [5-7]. These previous meta-analyses only included up to 10 studies, and a large amount of information was discarded in data extraction. In recent years, many studies comparing LESSA and CLA have been published, but there are still debates on the efficacy and safety of LESSA vs. CLA for adrenal surgery. Therefore, we conducted the current updated systematic review and meta-analysis to reassess the efficacy and safety of LESSA vs CLA for adrenal tumors.

\section{Aim}

The aim of the study is to reevaluate the efficacy and safety of LESSA vs CLA for adrenal lesions in terms of operative time, estimated blood loss $(\mathrm{EBL})$, transfusion, conversion rate, visual analog scale (VAS) score, complications, return to diet time, length of hospital stay, wound size, and cosmetic score.

\section{Material and methods}

\section{Search strategy}

We conducted a systematic literature search on PubMed, Ovid, and Scopus (up to February 2021). The search strategy was "(adrenalectomy) AND (laparoendoscopic OR endoscopic OR single-site OR single port OR single incision OR single access OR LESS) AND (laparoscopic OR laparoscopy)". The Preferred Reporting Items for Systematic Reviews and Meta-analysis (PRISMA) criteria were used for article selection (Figure 1). Two investigators (JJ and ZY) screened the titles and abstracts of potentially eligible studies independently. Relevant references were also checked for additional eligible studies.

\section{Inclusion and exclusion criteria}

Inclusion criteria: (1) original studies comparing LESSA to CLA for adrenal lesions; (2) English language studies only; (3) adult patients only. Exclusion criteria: (1) children's studies; (2) studies without primary or sufficient data (i.e., reviews, commentaries, conference abstracts).

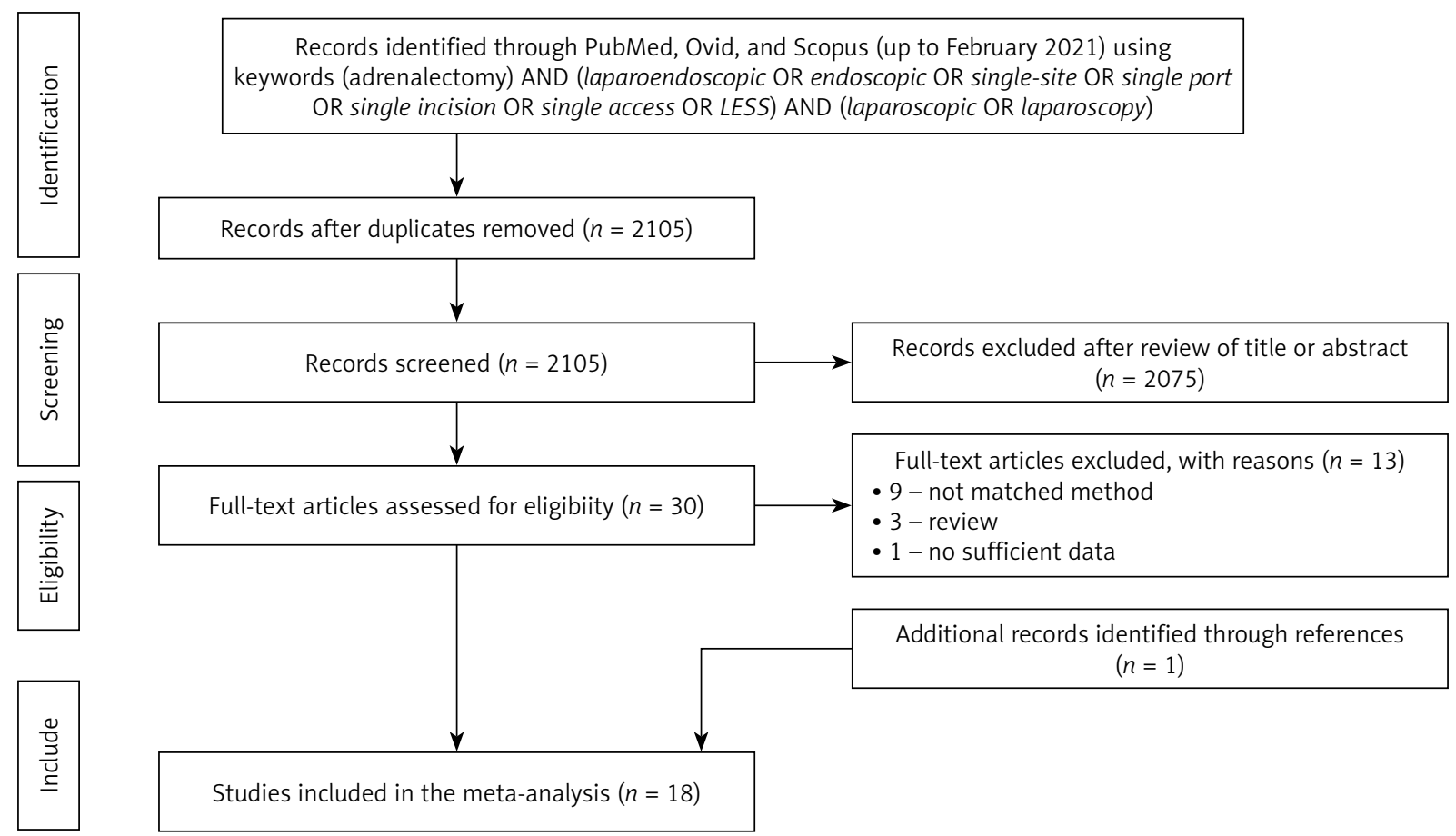

Figure 1. PRISMA flow diagram of the search strategy and identification of the included studies 


\section{Data extraction}

Data were extracted independently by two researchers ( $J$ and $Z Y$ ) using a predefined data extraction form, including demographic characteristics (age, gender, body mass index (BMI), tumor size and tumor side), peri-operative outcomes (operative time, estimated blood loss (EBL), transfusion and conversion), post-operative outcomes (visual analog scale (VAS) score, complications, return to diet time and length of hospital stay), and cosmetic outcomes (wound size and cosmetic score). Any discrepancy was resolved in consultation with ZT. Wound size was calculated as the sum of all wound sizes in CLA patients. VAS is a psychometric scale that is generally used in hospitals and clinics to conduct pain scale surveys to understand varying degrees of pain or discomfort experienced by a patient.

\section{Quality assessment}

Two researchers ( $\mathrm{JJ}$ and $\mathrm{ZT}$ ) independently assessed the evidence level of included studies accord- ing to the Oxford Centre for Evidence-based Medicine (Table I).

\section{Statistical analysis}

Cochrane Collaboration's Review Manager (RevMan) 5.4 software (Cochrane Collaboration, Oxford, UK) was adopted to analyze the effects of the outcomes. For continuous data, the weighted mean difference (WMD) with $95 \%$ confidence interval (Cl) was used. For dichotomous data, the odds ratio (OR) with $95 \%$ confidence interval $(\mathrm{Cl})$ was calculated. As only means and standard deviations are permitted for continuous data in RevMan 5.4, a validated mathematical model was used to convert median (range) to mean (standard deviation) for studies only reporting medians and ranges [8]. Heterogeneity was defined based on the Cochrane $\mathrm{Q} p$-value or ${ }^{2}$ statistic. If no significant heterogeneity was identified, a fixed-effects model was used. Otherwise, when significant heterogeneity was detected, a random-effects model was used. If $p>0.1$ or $1^{2}<50 \%$, a fixed-effects model was used, while if $p<0.1$ or

Table I. Basic characteristics of studies included in this meta-analysis

\begin{tabular}{|c|c|c|c|c|c|c|c|}
\hline \multirow[t]{2}{*}{ Study } & \multirow[t]{2}{*}{ Period } & \multirow[t]{2}{*}{ Design } & \multirow[t]{2}{*}{ Region } & \multicolumn{3}{|c|}{ LESSA/CLA } & \multirow[t]{2}{*}{ LE } \\
\hline & & & & Approach & Cases $(n)$ & FU [months] & \\
\hline Agcaoglu 2019 & 2008-2018 & RTP & Turkey & TP/TP & $44 / 36$ & $-/-$ & 4 \\
\hline Carvalho 2019 & 2009-2017 & RTP & Portugal & TP/TP & $41 / 59$ & 95.6/92.1 & 4 \\
\hline Chen 2019 & 2015-2018 & RTP & China & TP/TP & $40 / 36$ & $2 / 2$ & 4 \\
\hline Hasegawa 2013 & 2006-2011 & RTP & Japan & TP/TP & $50 / 56$ & $-/-$ & 4 \\
\hline Hirasawa 2014 & 2001-2013 & RTP & Japan & TP/TP & $70 / 140$ & $-/-$ & 4 \\
\hline Hora 2014 & 2008-2014 & RTP & Czech & TP/TP & $15 / 15$ & $-/-$ & 4 \\
\hline Inoue 2014 & 1996-2011 & RTP & Japan & $\mathrm{TP} / \mathrm{TP}$ & $11 / 54$ & $12.1 / 64.3$ & 4 \\
\hline Ishida 2013 & $2006-2010$ & RTP & Japan & $\mathrm{TP} / \mathrm{TP}$ & $10 / 10$ & $-1-$ & 4 \\
\hline Jeong 2009 & 2001-2009 & RTP & Korea & TP/TP & $9 / 17$ & $-/-$ & 4 \\
\hline Kwak 2011 & 2008-2009 & RTP & Korea & TP/TP & $10 / 12$ & $-1-$ & 4 \\
\hline $\operatorname{Lin} 2012$ & $2006-2009$ & RTP & China & $\mathrm{RP} / \mathrm{TP}$ & $21 / 28$ & $-1-$ & 4 \\
\hline Shi 2011 & 2009 & RTP & China & $\mathrm{RP} / \mathrm{RP}$ & $19 / 38$ & $-1-$ & 4 \\
\hline Tunca 2012 & 2006-2010 & RTP & Turkey & $\mathrm{TP} / \mathrm{TP}$ & $22 / 74$ & $-1-$ & 4 \\
\hline Vidal 2012 & 2010-2011 & $\mathrm{RCT}$ & Spain & $\mathrm{TP} / \mathrm{TP}$ & $20 / 20$ & $-1-$ & $2 b$ \\
\hline Walz 2010 & 2000-2009 & RTP & Germany & $\mathrm{RP} / \mathrm{RP}$ & $47 / 47$ & $-1-$ & 4 \\
\hline Wang 2012 & 2009-2011 & RTP & China & $\mathrm{TP} / \mathrm{TP}$ & $13 / 26$ & $-1-$ & 4 \\
\hline Wang 2016 & 2011-2015 & RTP & China & $\mathrm{RP} / \mathrm{RP}$ & $51 / 65$ & 20.2 & 4 \\
\hline Wen 2013 & 2001-2011 & RTP & China & $\mathrm{RP} / \mathrm{RP}$ & $27 / 54$ & $3.42 / 4.27$ & 4 \\
\hline
\end{tabular}

LESSA - laparoendoscopic single-site adrenalectomy, CLA - conventional laparoscopic adrenalectomy, FU - follow-up, LE - level of evidence according to the Oxford Centre for Evidence-based Medicine, RTP - retrospective, RCT - randomized controlled trial, RP - retroperitoneal, TP - transperitoneal. 
$I^{2}>50 \%$, a random-effects model was used. Subgroup analysis was used to find sources of heterogeneity. A $p$-value $<0.05$ was considered statistically significant. To evaluate publication bias, funnel plots were examined.

\section{Results}

Overall, eighteen studies including 1307 patients (LESSA 520; CLA 787) were included in this study (Figure 1). Table I shows the basic characteristics and quality assessment of the included studies [9-26].

The demographic results of this meta-analysis showed similar age, gender, body mass index (BMI), and tumor side. Sixteen studies including $1186 \mathrm{pa}-$ tients (LESSA 483; CLA 703) reported tumor size [9-14, 16-18, 20-26]. Patients undergoing LESSA have a smaller mean tumor size $(W M D=-0.53 \mathrm{~cm}$, $95 \% \mathrm{Cl}:-0.81$ to $-0.24 ; p<0.001$ ) (Supplementary Figures S1, S2).

All the eighteen studies reported operative time [9-26]. The meta-analysis of these studies showed longer operative time for LESSA (WMD $=13.86 \mathrm{~min}$, $95 \% \mathrm{Cl}: 4.43$ to $23.30 ; p=0.004)$. EBL data were available in twelve studies including 896 patients (LESSA 331; CLA 565) [9, 11, 13-17, 20, 21, 24-26]. Thirteen studies including 880 patients (LESSA 334; CLA 546) reported transfusion [13, 15-26]. Seventeen studies including 1282 patients (LESSA 483; CLA 799) reported conversion [9, 10, 12-26]. The meta-analysis of these studies showed similar EBL $(\mathrm{WMD}=4.04 \mathrm{ml}, 95 \% \mathrm{Cl}:-2.83,10.92 ; p=0.25)$, transfusion rate $(\mathrm{OR}=0.96,95 \% \mathrm{Cl} ; 0.17$ to 5.43 ; $p=0.96)$, and conversion rate $(\mathrm{OR}=2.77,95 \% \mathrm{Cl}$ : 0.93 to $8.25 ; p=0.07$ ) (Figure 2).

Eight studies including 585 patients (LESSA 236; CLA 349) reported the VAS score $[9,11,20-22,24-$ 26]. LESSA had a better VAS score (WMD $=-0.56$, $95 \% \mathrm{Cl}:-1.01$ to $-0.11 ; p=0.02)$. Nine studies including 693 patients (LESSA 256; CLA 437) reported the data of return to diet time [10, 13, 17-20, 24-26]. The meta-analysis of these studies showed a shorter return to diet time for LESSA (WMD $=-0.27$ days, $95 \% \mathrm{Cl}:-0.52$ to $-0.03 ; p=0.03)$. Fifteen studies in cluding 1053 patients (LESSA 414; CLA 639) reported length of hospital stay $[9,10,13,14,16-26]$. The results showed a shorter length of hospital stay for LESSA (WMD $=-0.56$ days, $95 \% \mathrm{Cl}:-1.01$ to -0.11 ; $p=0.01$ ). All the eighteen studies reported complications [9-26]. The results showed no significant dif- ference between the two groups $(\mathrm{OR}=0.98,95 \% \mathrm{Cl}$ : 0.56 to $1.70 ; p=0.93$ ) (Figure 3).

Four studies including 293 patients (LESSA 110; CLA 183) reported wound size [20, 24-26]. LESSA was associated with smaller wound size (WMD = $-2.72 \mathrm{~cm}, 95 \% \mathrm{Cl}:-3.50$ to $-1.94 ; p<0.001)$. Three studies including 220 patients (LESSA 75; CLA 145) reported the cosmetic score $[15,24,25]$. The metaanalysis of these studies showed no statistically significant differences for cosmetic score between the two groups $(\mathrm{OR}=0.95,95 \% \mathrm{Cl}$ : -0.13 to 2.02 ; $p=0.08$ ). (Supplementary Figure S3).

Since most of the studies used the transperitoneal approach, especially the transperitoneal approach through umbilical incision (TPU), the aesthetics are particularly obvious. Therefore, we analyzed the studies of the transperitoneal approach and performed subgroup analysis of the transperitoneal approach through subcostal incision (TPS) and TPU.

The demographic results of subgroup analysis showed similar age, gender, BMI, and tumor side. Twelve studies including 838 patients (LESSA 339; CLA 499) reported tumor size [9-14, 16-18, 21, 22, 24]. Patients undergoing LESSA had smaller tumor size $(\mathrm{WMD}=-0.61 \mathrm{~cm}, 95 \% \mathrm{Cl}:-1.02$ to $-0.21 ; p=$ $0.003)$. The subgroup analysis showed a consistent result for TPU (WMD $=-1.00 \mathrm{~cm}, 95 \% \mathrm{Cl}:-1.61$ to $-0.39 ; p=0.001$ ). However, the subgroup analysis of TPS showed no significant difference (WMD $=-0.15$ $\mathrm{cm}, 95 \% \mathrm{Cl}:-0.45$ to $0.16 ; p=0.35$ ) (Supplementary Figures S4, S5).

Thirteen studies reported operative time, including 903 patients (LESSA 350; CLA 553) [9-18, 21, 22, 24]. The results showed longer operative time for LESSA (WMD = $14.01 \mathrm{~min}, 95 \% \mathrm{Cl}: 1.20$ to 26.83; $p=0.03)$. The subgroup analysis showed consistent result for TPS (WMD = $14.39 \mathrm{~min}, 95 \% \mathrm{Cl}: 8.99$ to $19.79 ; p<0.001$ ). The subgroup analysis of TPU showed no significant difference $(W M D=11.35 \mathrm{~min}$, $95 \% \mathrm{Cl}:-10.55$ to $33.25 ; p=0.31)$. Nine studies including 642 patients (LESSA 234; CLA 408) reported EBL $[9,11,13-17,21,24]$. Eight studies including 483 patients (LESSA 169; CLA 483) reported transfusion [13, 15-18, 21, 22, 24]. Twelve studies including 885 patients (LESSA 318; CLA 567) reported conversion $[9,10,12-18,21,22,24]$. The results showed similar EBL (WMD $=-1.23 \mathrm{ml}, 95 \% \mathrm{Cl}:-3.65,1.18$; $p=0.32)$, transfusion rate $(\mathrm{OR}=0.96,95 \% \mathrm{Cl}: 0.17$ to $5.43 ; p=0.96)$, and conversion rate $(\mathrm{OR}=1.84$, $95 \% \mathrm{Cl}: 0.53$ to $6.43 ; p=0.34$ ). The subgroup analy- 

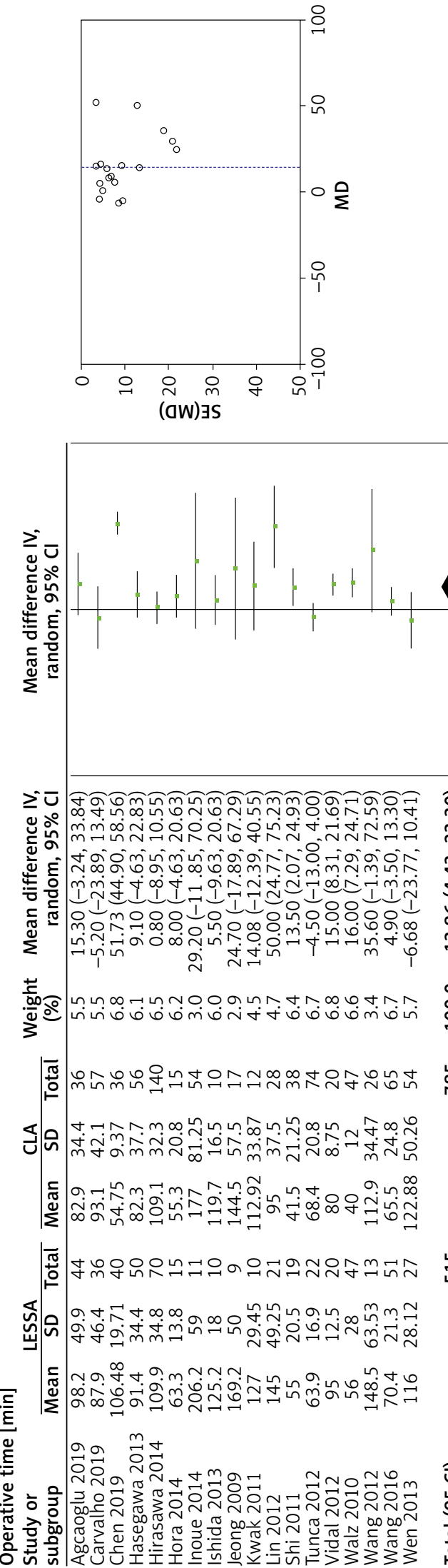
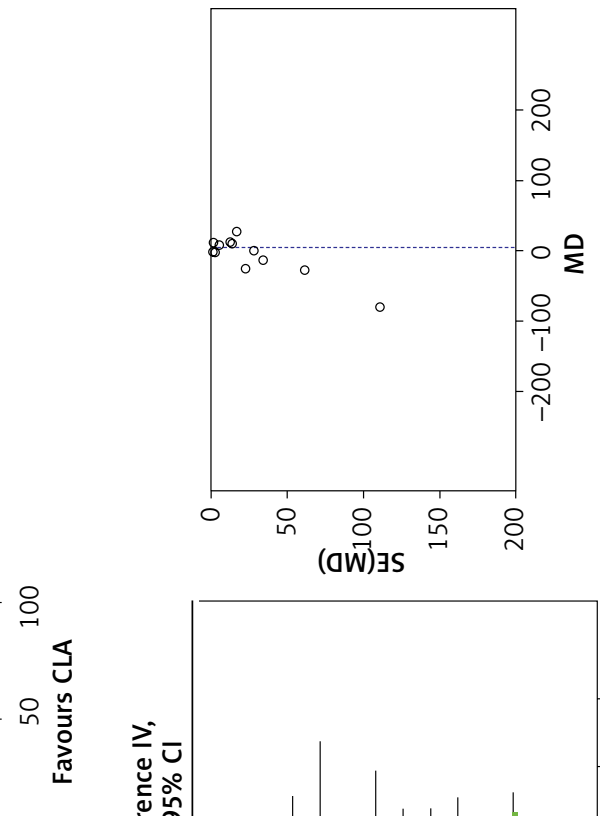

$\circ$
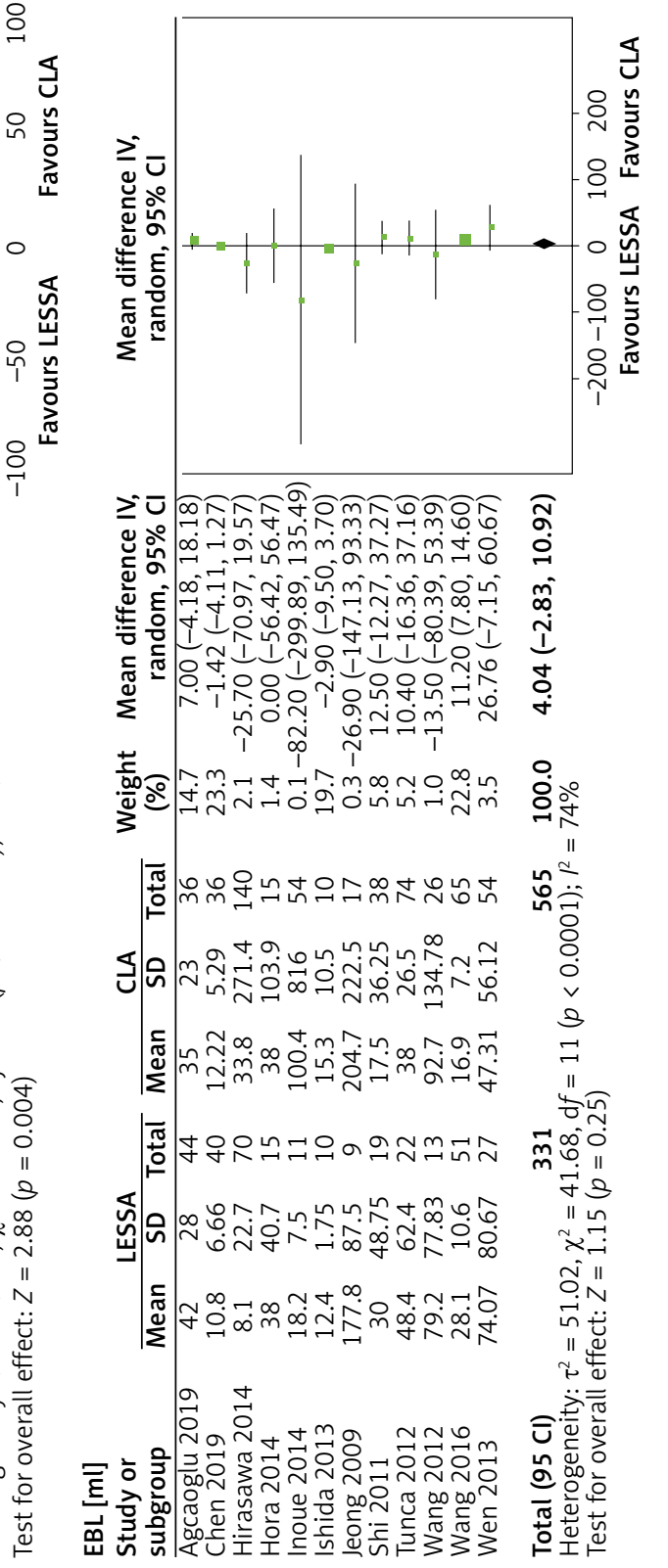

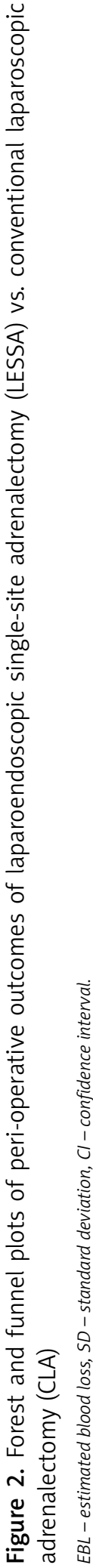



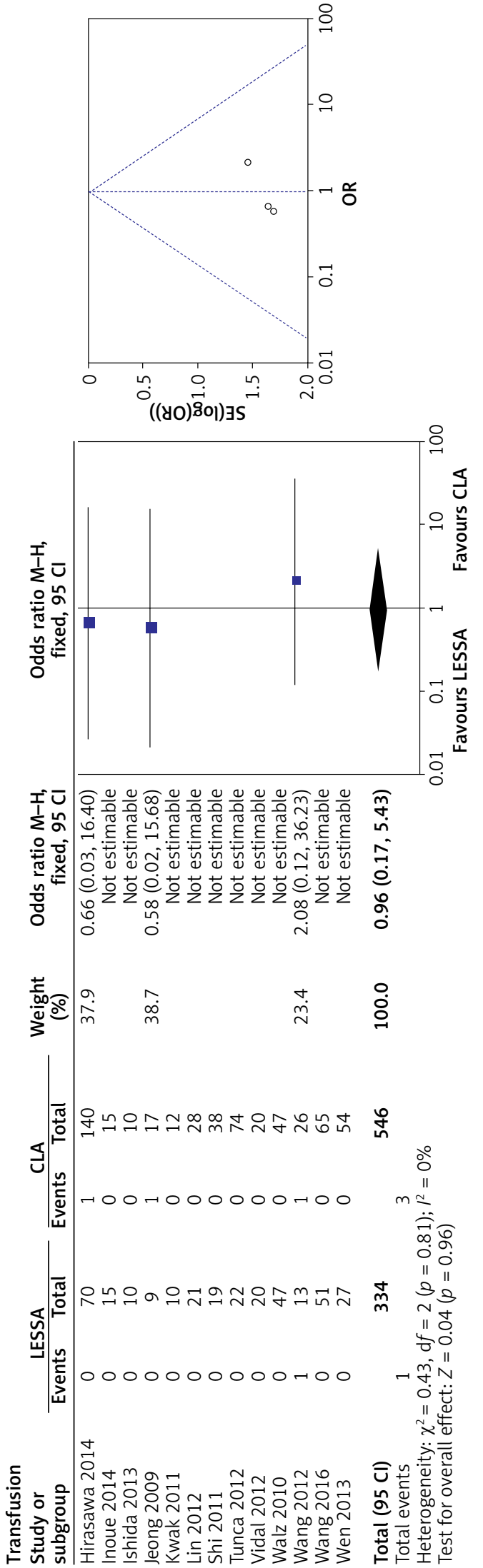
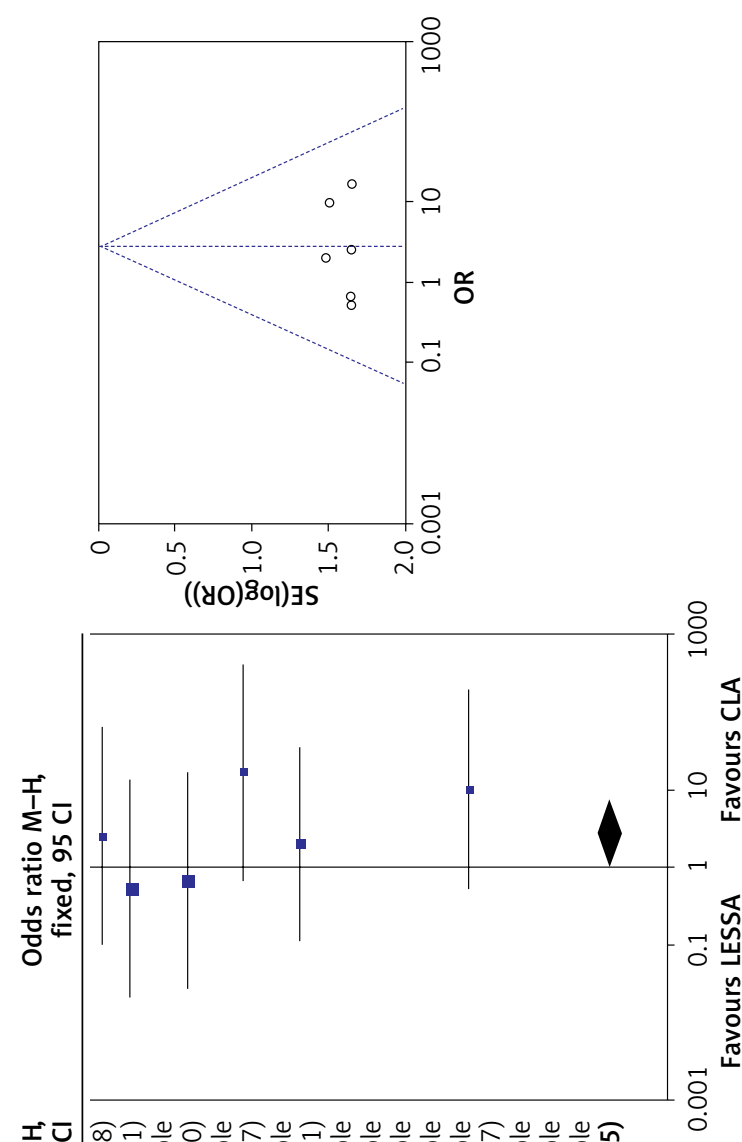

푸응

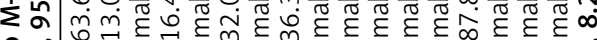

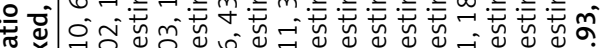

尊

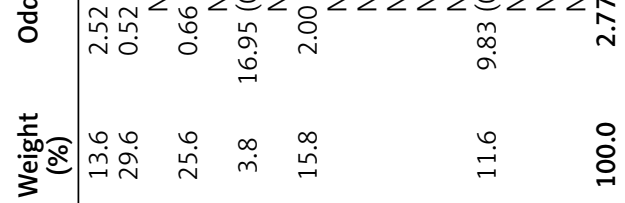

$\overline{\mathbb{g}}$

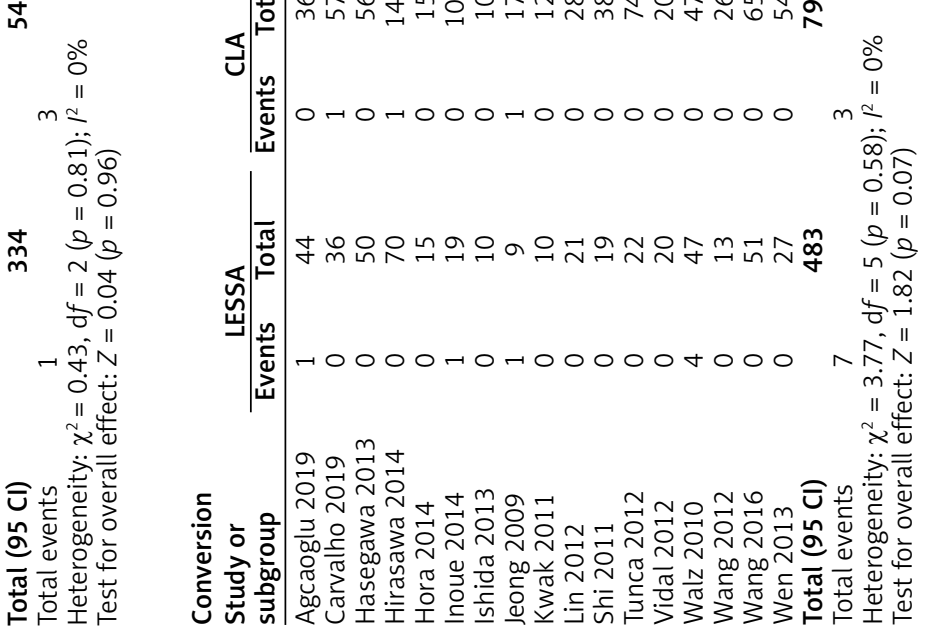



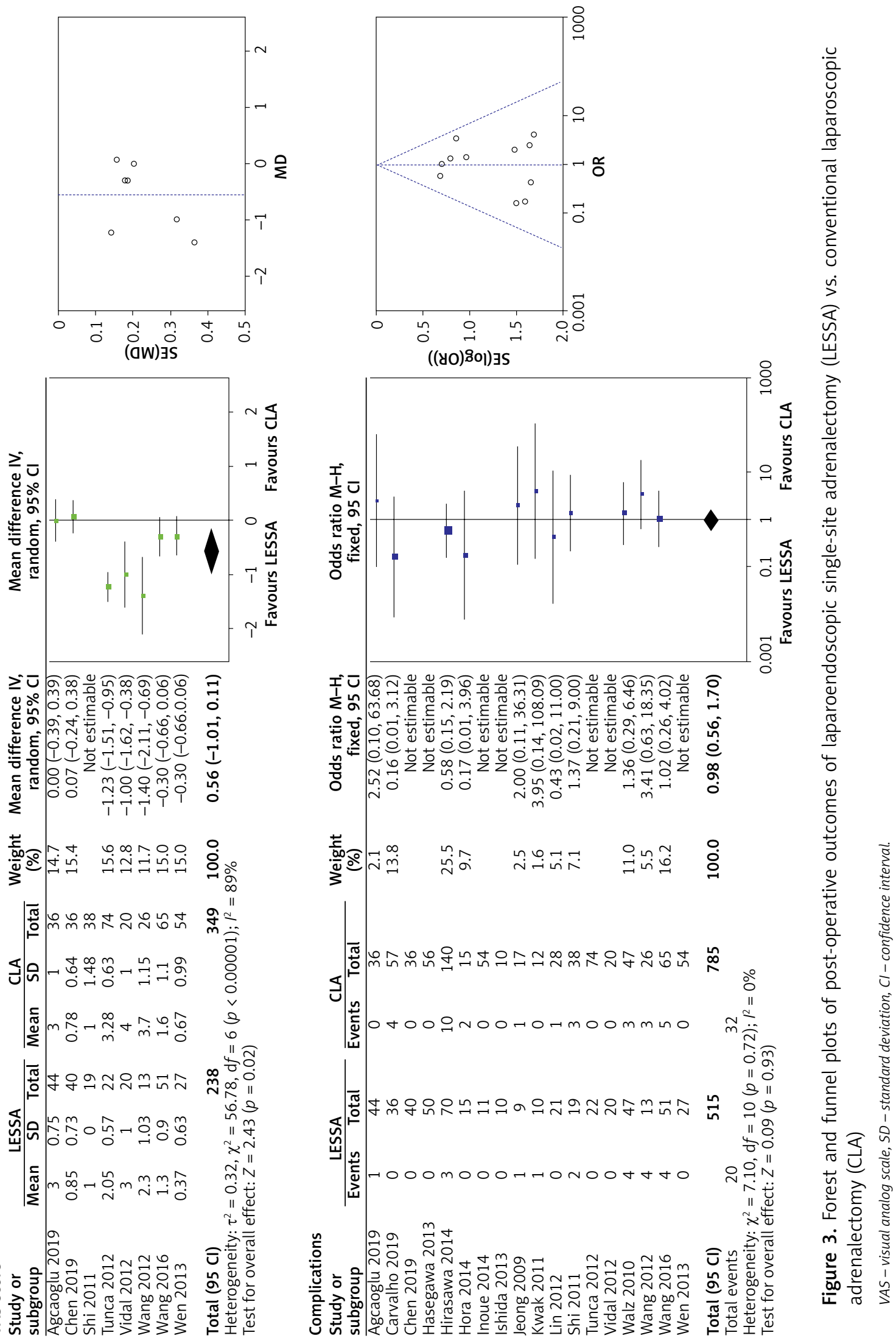

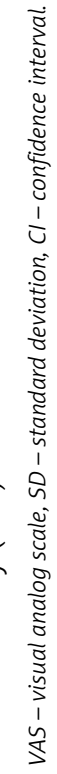



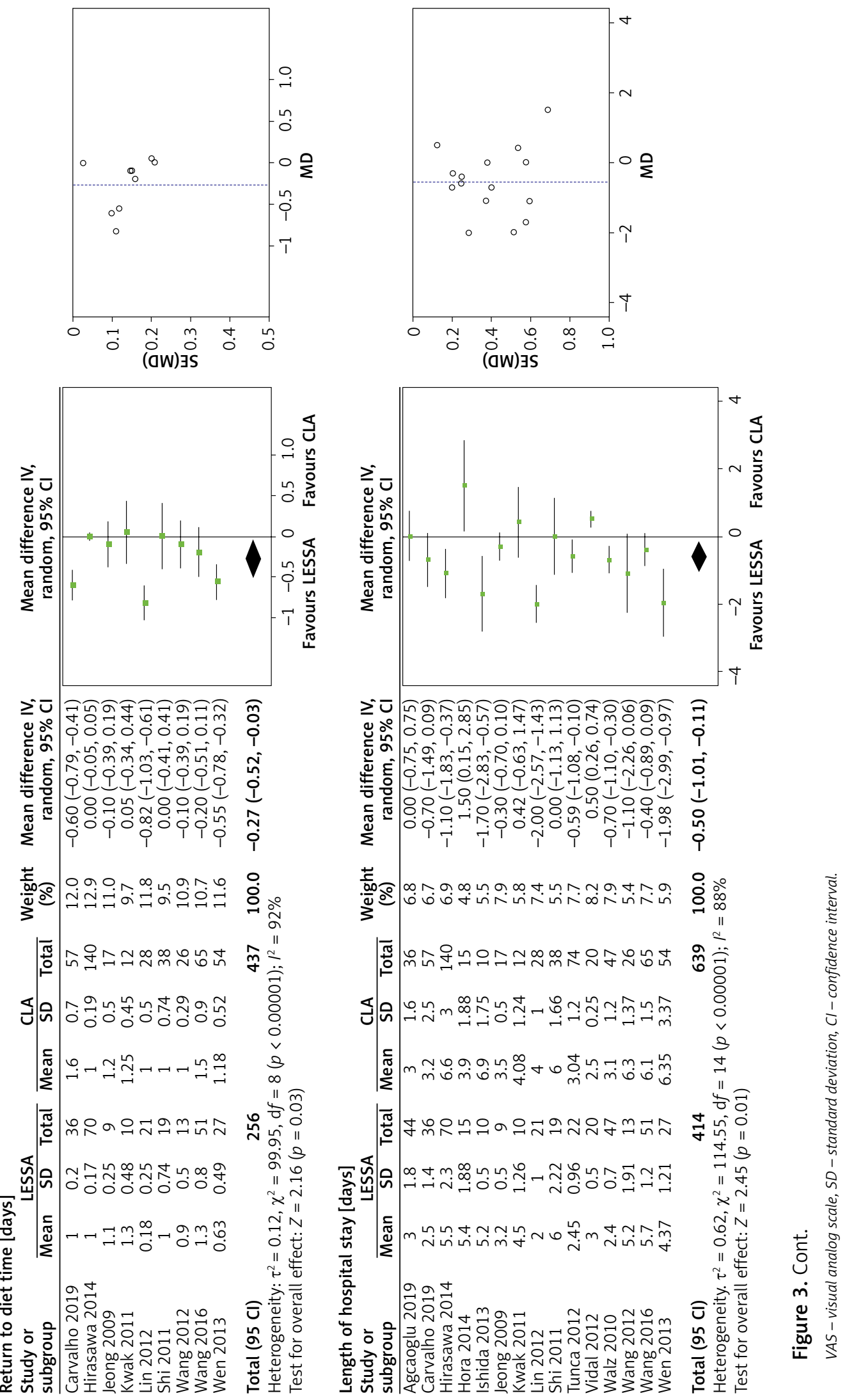

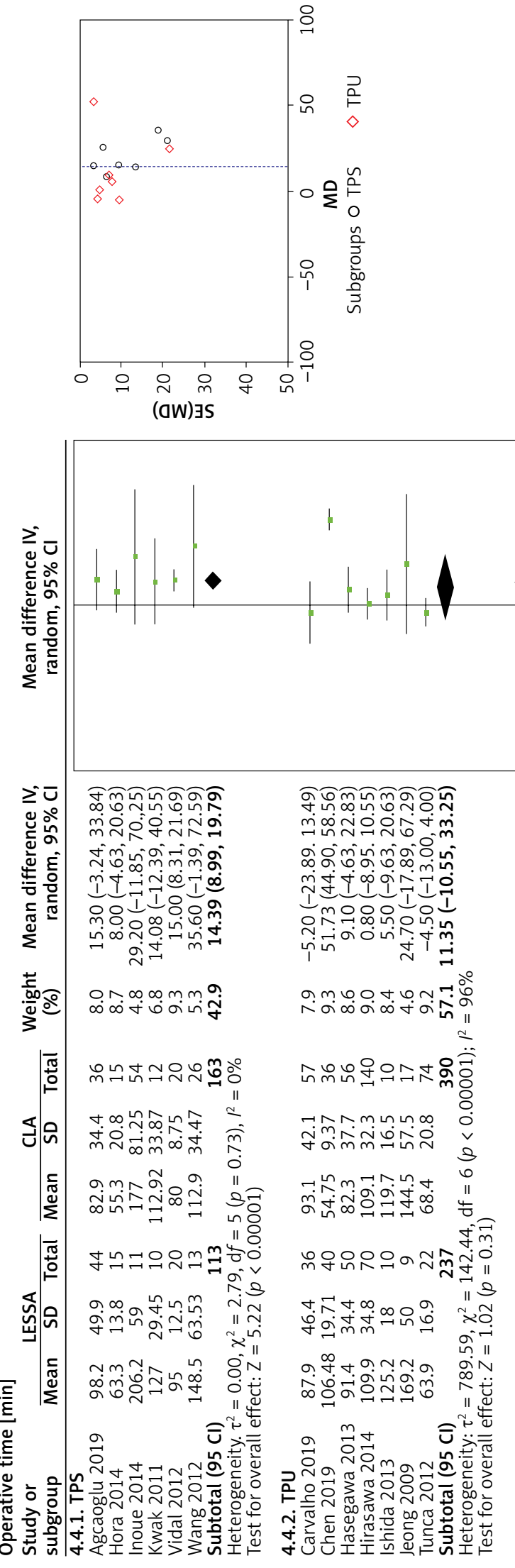
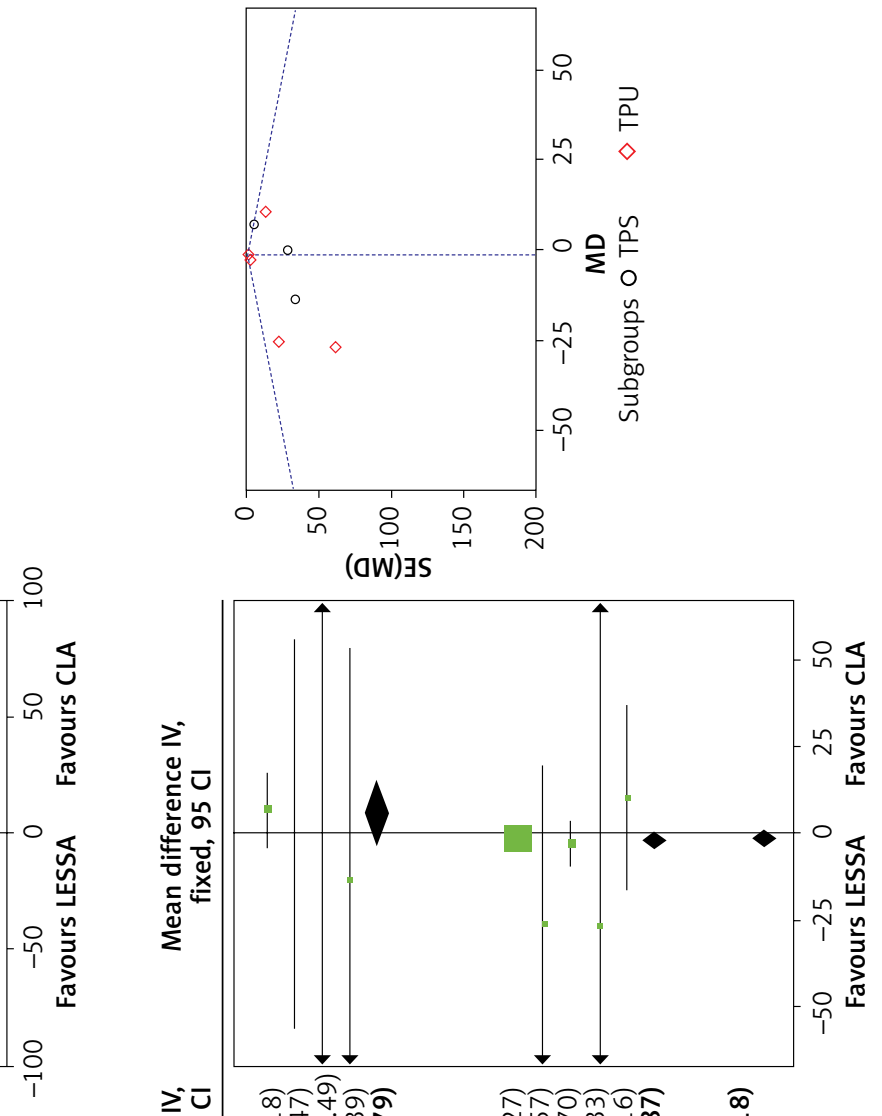

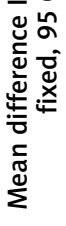

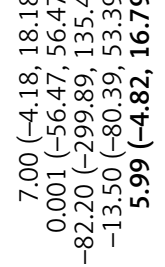

蒿

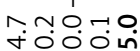

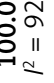

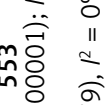

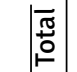

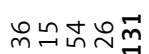

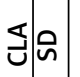

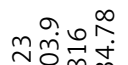

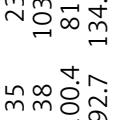

离

$\pi \frac{\pi}{0}$

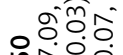

mª.

䄈

$\forall n=m m$ 듕

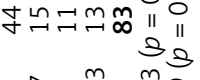

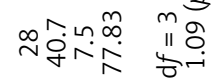

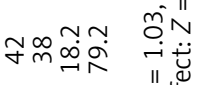

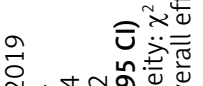

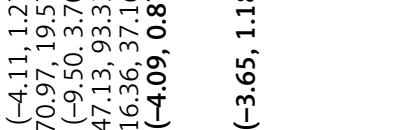

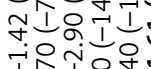

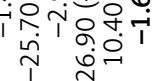

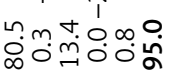

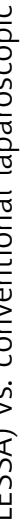

(1)

mitar d क

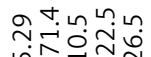

ปั ठ

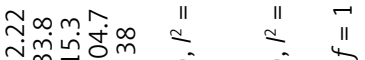

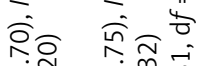

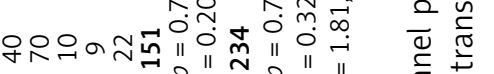
brinnt th on

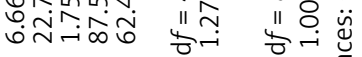

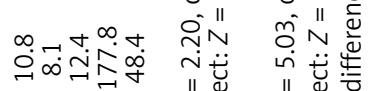

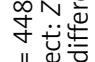

离产 บิ nू.

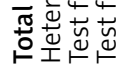




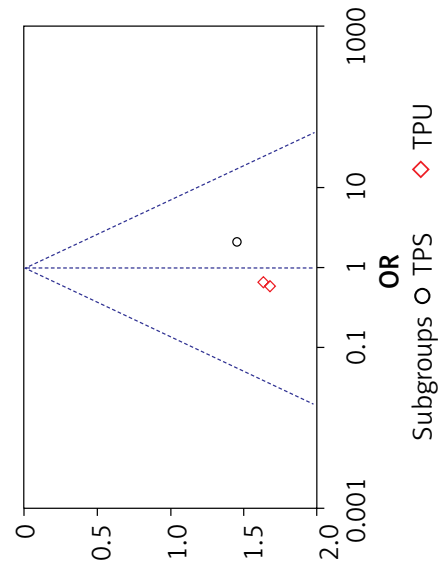

((४)

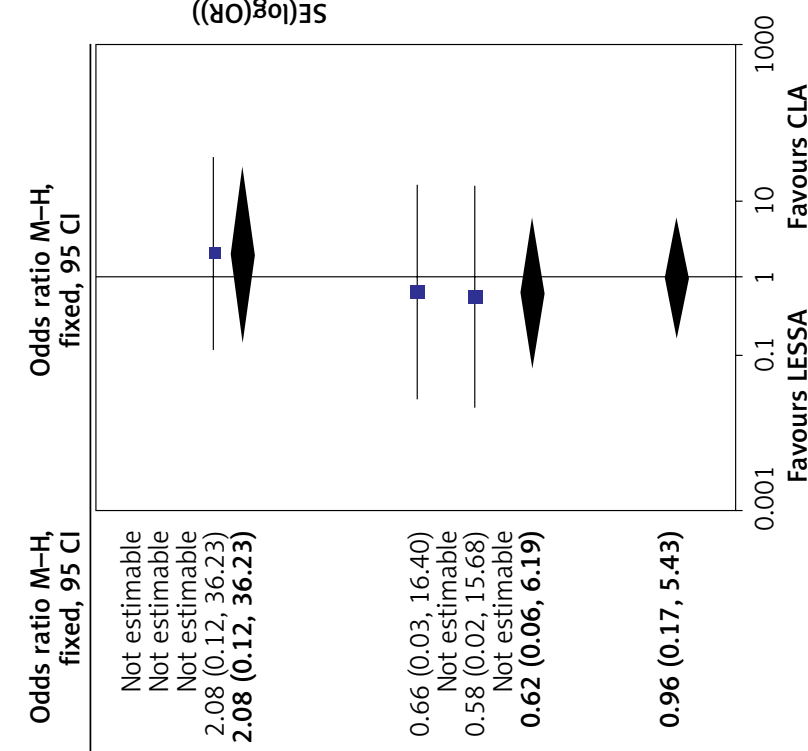

누ำำก

|

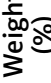

$\stackrel{\sim}{\sim} \ddot{\sim}$

$\stackrel{a}{\stackrel{n}{m}} \stackrel{\infty}{m} \stackrel{o}{\stackrel{\infty}{i}}$

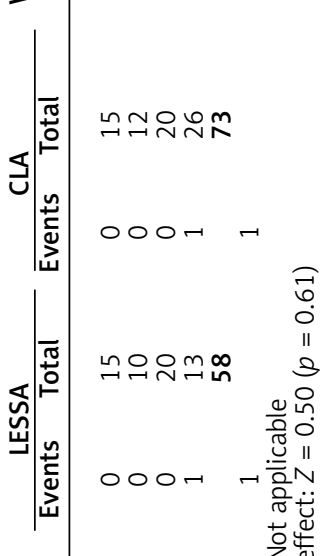

ิิ

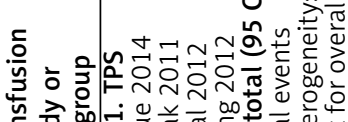

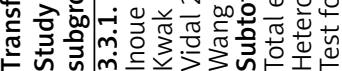

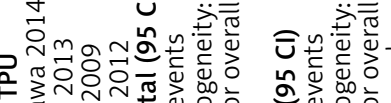

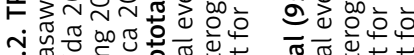

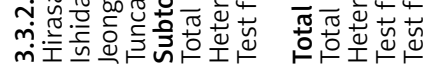

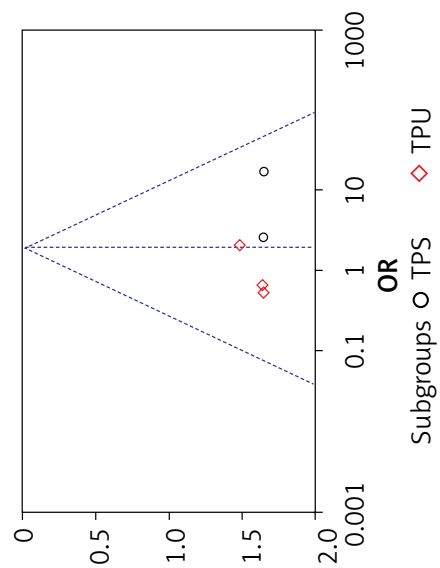

$(($ yo) 80 이) $) \mathrm{S}$

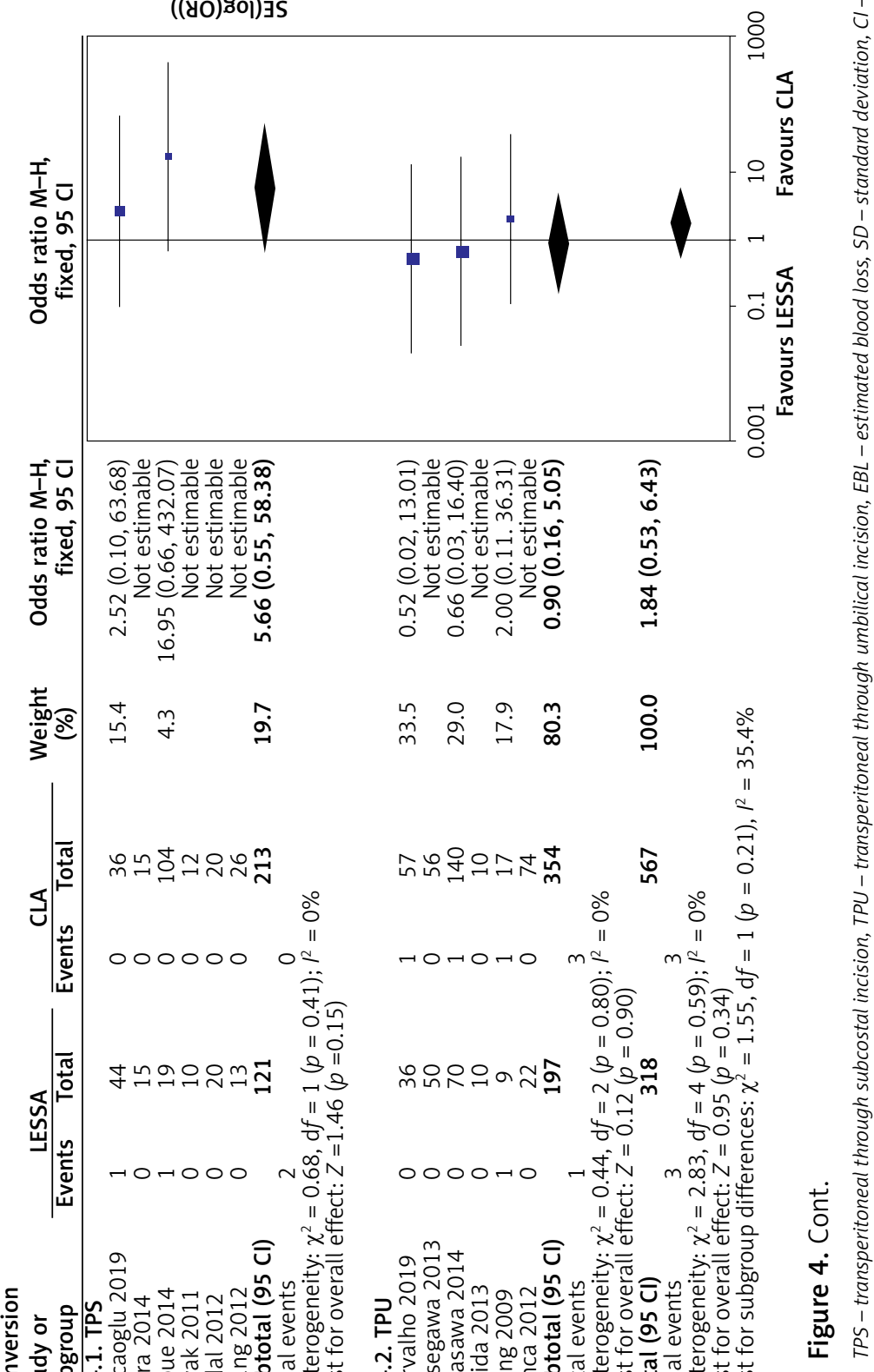



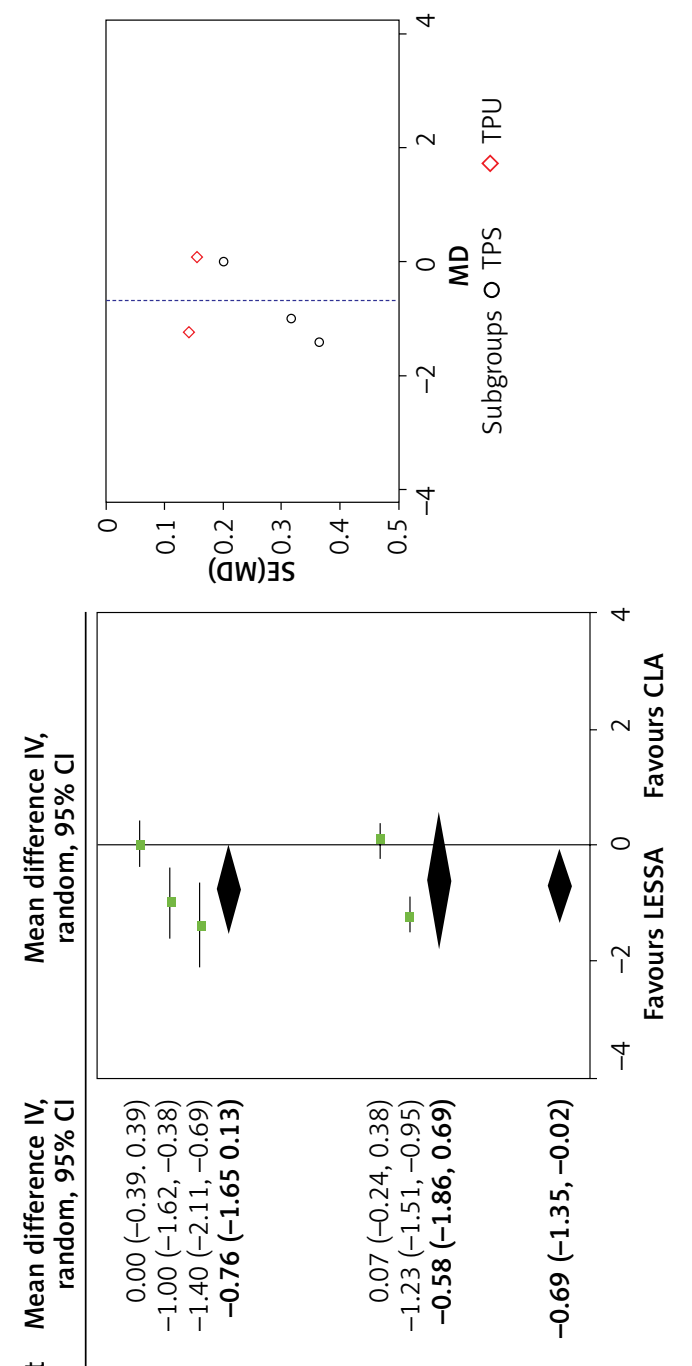

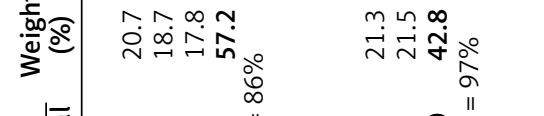

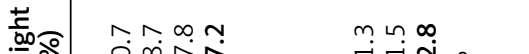

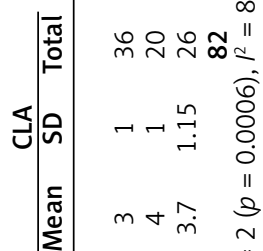

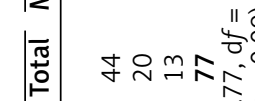

क्ष்

产

赔

을

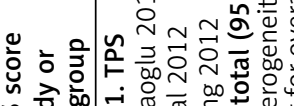

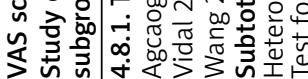

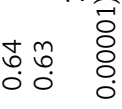

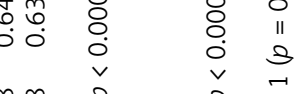

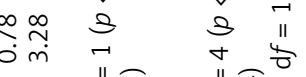

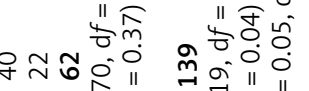

००

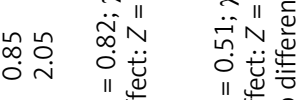

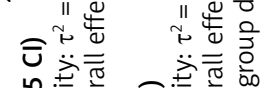

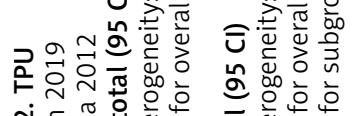

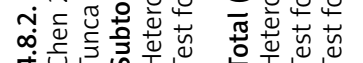

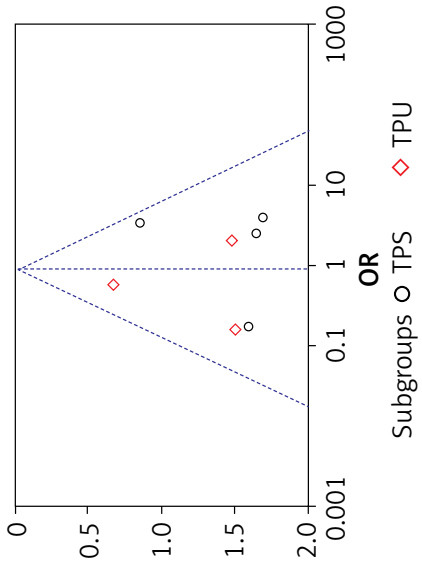

((yo)이이) $\mathrm{SS}$

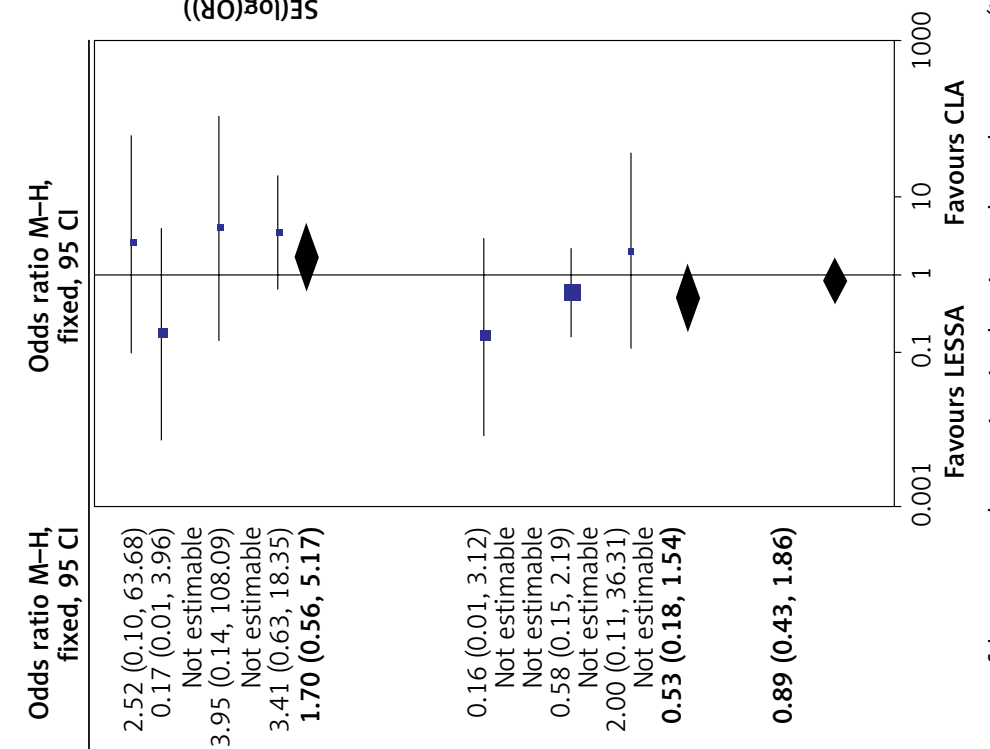

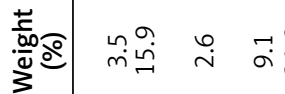

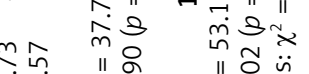

퐁

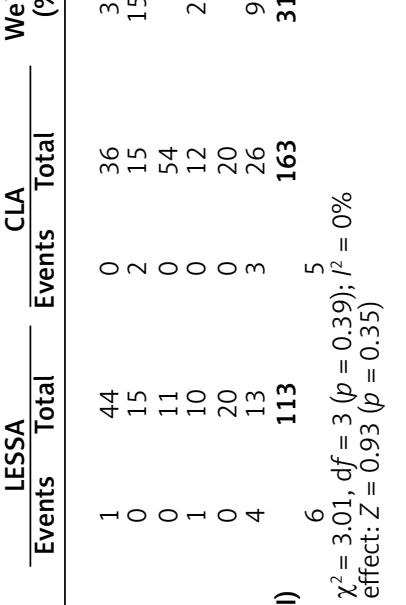

告

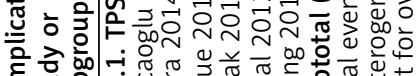

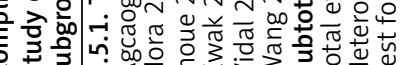

ฐ

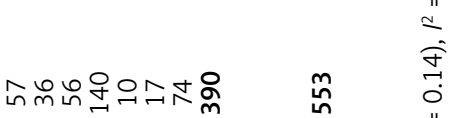
ลे 3

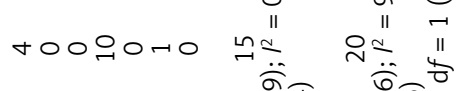

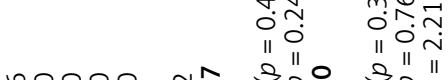

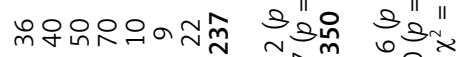

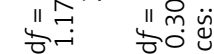

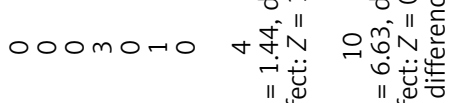

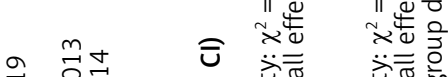

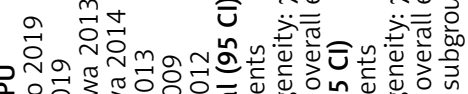

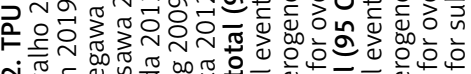
نู่

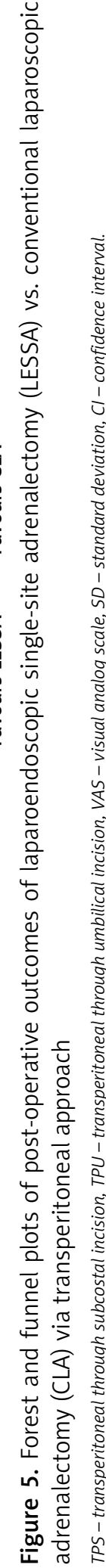



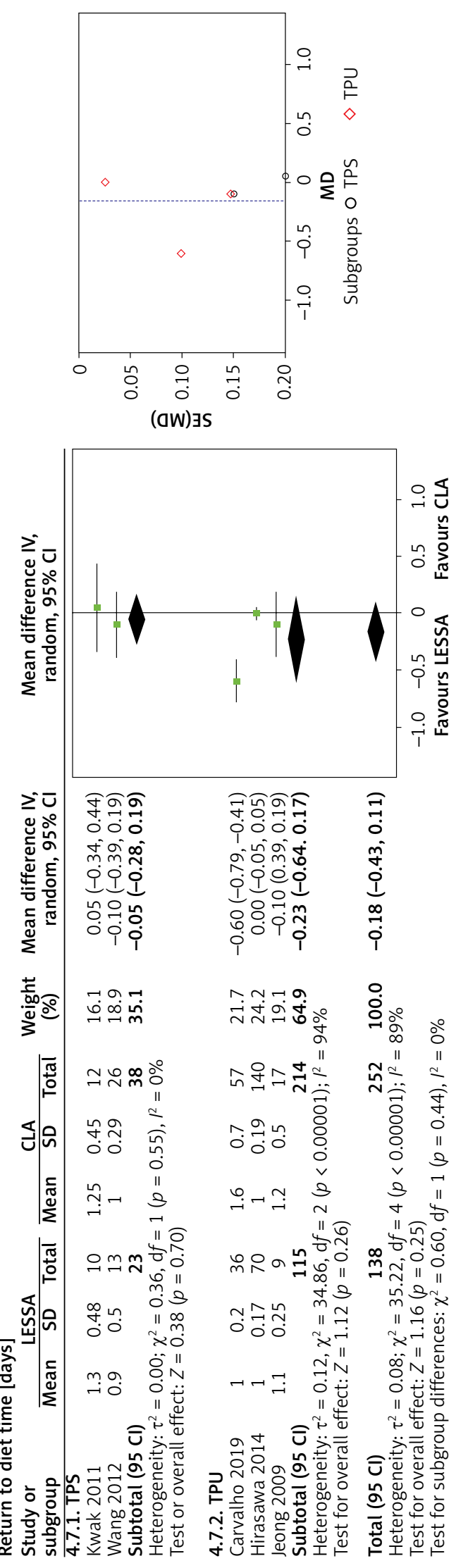

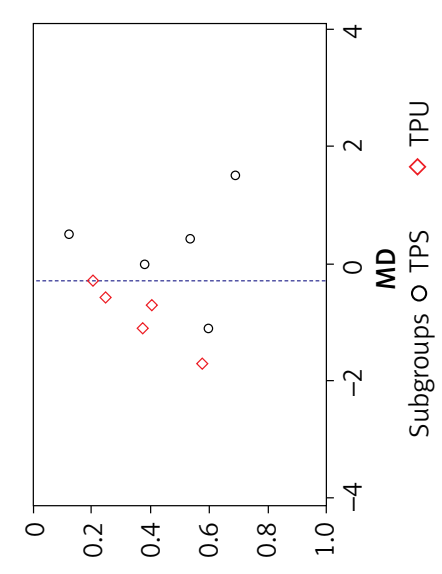

(aw) $\exists S$

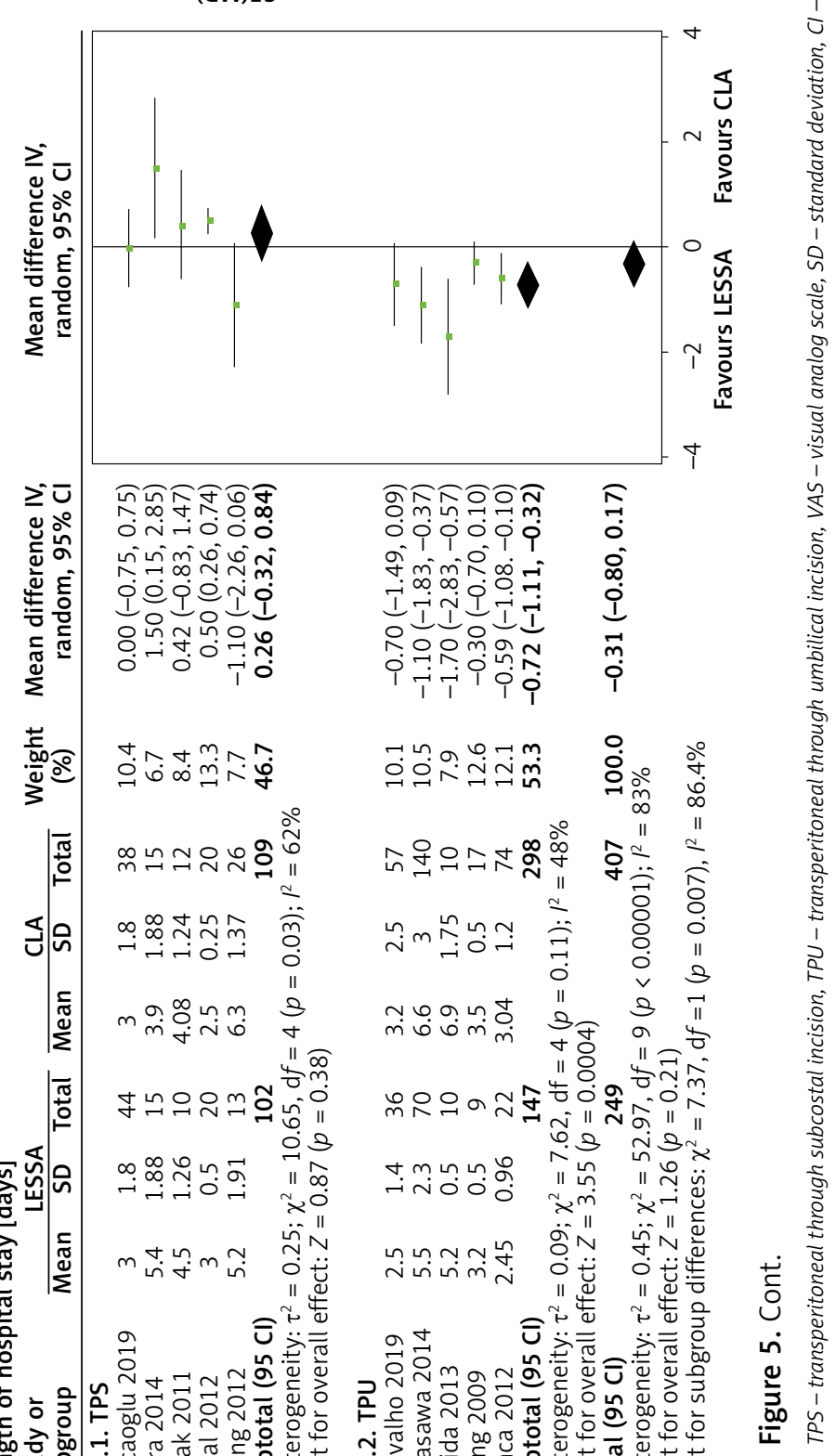


sis of EBL, transfusion, and conversion showed consistent results (Figure 4).

Five studies including 331 patients (LESSA 139; CLA 192) reported the VAS score $[9,11,21,22,24]$. LESSA showed a better VAS score (WMD $=-0.69$, $95 \% \mathrm{Cl}:-1.35$ to $-0.02 ; p=0.04)$. However, the subgroup analysis of TPS and TPU showed no significant difference. Thirteen studies including 903 patients (LESSA 350; CLA 553) reported complications [9-18, $21,22,24]$. Five studies including 390 patients (LESSA 138; CLA 252) reported return to diet time $[10,13$, $17,18,24]$. The results showed similar complications $(\mathrm{OR}=0.89,95 \% \mathrm{Cl}: 0.43$ to $1.86 ; p=0.76)$ and return to diet time (WMD $=-0.16$ days, $95 \% \mathrm{Cl}:-0.43$ to $0.11 ; p=0.25$ ). The subgroup analysis of complications and return to diet time showed consistent results. Ten studies including 656 patients (LESSA 249; CLA 407) reported length of hospital stay [9, 10, $13,14,16-18,21,22,24]$. There was no significant difference in length of hospital stay (WMD $=-0.31$ days, $95 \% \mathrm{Cl}:-0.80$ to $0.17 ; p=0.21$ ). However, the subgroup analysis of TPU showed shorter length of hospital stay for LESSA (WMD $=-0.72$ days, $95 \% \mathrm{Cl}$ : -1.11 to $-0.32 ; p<0.001$ ) (Figure 5 ).

There was no significant publication bias in this study.

\section{Discussion}

Conventional laparoscopic adrenalectomy (CLA) is the gold standard method for the treatment of small adrenal tumors. Recently, both the transperitoneal approach and retroperitoneal approach of CLA have demonstrated safety, efficacy and very low morbidity [27]. In the past decade, more and more studies have explored single port laparoscopic techniques to reduce or even eliminate surgical incision scars. The postoperative incision of the LESSA via the umbilical approach is hidden in the umbilicus without any visible scars, thereby improving cosmetic satisfaction. Today, laparoscopic adrenalectomy can be performed by LESSA without obvious surgical scars. However, the steep learning curve and increased cost-effectiveness limited its application. In addition, the efficacy and safety of LESSA have been controversial. In recent years, many studies comparing LESSA and CLA have been published. Indeed, there is an urgent need to analyze the current evidence and draw objective conclusions about these two procedures.
In this meta-analysis, patients treated with LESSA and CLA were similar in age, gender, BMI, and tumor side. The tumor size was smaller in the LESSA group. This could be due to the inherent selection bias, because LESSA is more technically difficult. The transperitoneal approach data showed similar results. However, the subgroup analysis of TPS showed similar tumor size. This might be related to selection bias, rather than the surgical approach itself.

The meta-analysis of this study showed similar EBL, transfusion rate, conversion rate, and complications compared with previous meta-analyses. The transperitoneal approach data showed consistent results. This might be due to the small adrenal tumors included in the studies, with an average of $2-3 \mathrm{~cm}$. The surgical difficulty is relatively low, and the incidence rates of intraoperative bleeding, blood transfusion, conversion, and complications were very low. These results reflected the safety of the two procedures for small adrenal lesions. Previous meta-analyses reported inconsistent operative time. Two studies reported a significantly increased operative time for LESSA [5, 6], while another study reported similar operative time [7]. Our meta-analysis showed significantly prolonged operative time. The transperitoneal approach data also showed consistent results. However, the subgroup analysis of TPU showed similar operative time. This could be well explained by the tumor size issue. The tumor size of the two groups under the TPS approach was similar, and LESSA was more difficult. Therefore, the operative time of LESSA was longer. The tumor size of the LESSA group under the TPU approach was smaller, and the operative time was similar. This reasonably explained the longer operation time required for LESSA.

Postoperative pain is a very important indicator of safety. LESSA was expected to reduce postoperative pain because it reduced the number of ports and shortened the total incision length. However, a larger single incision might increase pain. The VAS score is a relatively objective pain assessment tool. Therefore, this study only used the VAS score to assess postoperative pain. Our results showed that the pain in the LESSA group was slightly less than that in the CLA group. However, the results reported in recent years did not differ significantly in the VAS results. Our result showed a shorter return to diet time. However, the transperitoneal approach data showed similar return to diet time. This might be because the intestine 
interference of the transperitoneal approach was greater than the impact of the operation itself. Our study showed shorter length of hospital stay for LESSA than CLA. However, the subgroup analysis showed that the length of hospital stay in the two groups was similar. These results were quite consistent with operative time and tumor size. Further studies should pay attention to whether there is an inevitable relationship between them.

LESSA was clearly associated with smaller wound size. Three studies reported the cosmetic score. Our meta-analysis showed a similar cosmetic score. Inoue and colleagues reported that the cosmesis score of CLA was significantly lower than LESSA at 3 months postoperatively $(p=0.0033)$. However, the cosmesis score in the CLA group was gradually elevated at 6 months postoperatively, then the score was equivalent to that in the LESSA group at 12 months postoperatively [28]. Lucas et al. reported that patients were predominantly concerned with complications, success, convalescence, and wound pain and were less concerned with cosmesis. However, female patients, young patients, and patients with benign diseases had increased concern about cosmesis [29]. Our result might be related to older age of patients, lower cosmetic requirements, and small scars in both groups. Of course, the small sample size and shorter follow-up time would also affect the results. Future randomized trials with larger samples and longer-term follow-up are needed to evaluate the efficacy of LESSA.

However, technical disadvantages of LESSA, including instrument clashing, suboptimal ergonomics and lack of instrument triangulation, increase the difficulty. Therefore, LESSA has not been widely used. Currently, LESSA is only being used in select sites, and its use does not appear to be growing rapidly. The solution for widespread adoption of the single-site adrenalectomy might be the use of the single-site robotic system, which would reduce the surgical technical difficulty. Robotic surgery has the following advantages over laparoscopic surgery: 3D enhanced vision, articulated instrumentation, reduced tremor with improved dexterity and better surgeon comfort [30]. Single-site robotic adrenalectomy was performed by Park for the first time in 2011 [31]. However, studies about single-site robotic adrenalectomy in the literature are scarce. More randomized controlled trials and prospective studies are needed to evaluate the oncologic results, cosmetic appearance and postoperative complications.
There are some limitations to this study. First, most of the studies were retrospective studies with a small sample size, which limited the quality of the results. Second, the single-port access devices were not standardized. Third, the surgical approach was not consistent. Fourth, the follow-up time was unclear. Fifth, the cosmetic data were insufficient. Sixth, the pathological data were inconsistent. A few studies included malignant adrenal tumors, which might cause heterogeneity of perioperative outcomes. Last but not least, we did not analyze surgical cost because there were not enough data. More multicenter randomized controlled trials with a long follow-up time are needed to further confirm the results.

\section{Conclusions}

LESSA is significantly better in postoperative pain, time to diet, length of hospital stay and wound size, but the operative time is significantly longer. The robotic single-site adrenalectomy could overcome the surgical technical difficulty of LESSA, which might be the future of adrenalectomy.

\section{Acknowledgments}

We thank Dr. Chawnshang Chang at the University of Rochester Medical Center for helping with the preparation of the manuscript.

This study was supported by the National Natural Science Foundation of China (grant number 81802544) and the Natural Science Foundation of Hebei Province (grant number H2020206146).

\section{Conflict of interest}

The authors declare no conflict of interest.

\section{References}

1. Poulose BK, Holzman MD, Lao OB, et al. Laparoscopic adrenalectomy: 100 resections with clinical long-term follow-up. Surg Endosc 2005; 19: 379-85.

2. Weiss HG, Brunner W, Biebl MO, et al. Wound complications in 1145 consecutive transumbilical single-incision laparoscopic procedures. Ann Surg 2014; 259: 89-95.

3. Carus T. Current advances in single-port laparoscopic surgery. Langenbecks Arch Surg 2013; 398: 925-9.

4. Goel R, Lomanto D. Controversies in single-port laparoscopic surgery. Surg Laparosc Endosc Percutan Tech 2012; 22: 380-2.

5. Hu Q, Gou Y, Sun C, et al. A systematic review and meta-analysis of current evidence comparing laparoendoscopic single-site adrenalectomy and conventional laparoscopic adrenalectomy. J Endourol 2013; 27: 676-83. 
6. Wang L, Wu Z, Li M, et al. Laparoendoscopic single-site adrenalectomy versus conventional laparoscopic surgery: a systematic review and meta-analysis of observational studies. J Endourol 2013; 27: 743-50.

7. Wu S, Lai H, Zhao J, et al. Laparoendoscopic single-site adrenalectomy versus conventional laparoscopic adrenalectomy: an updated meta analysis. Urol J 2016; 13: 2590-8.

8. Hozo SP, Djulbegovic B, Hozo I. Estimating the mean and variance from the median, range, and the size of a sample. BMC Med Res Methodol 2005; 5: 13.

9. Agcaoglu O, Sengun B, Senol K, et al. Comparison of technical details and short-term outcomes of single-incision versus multiport laparoscopic adrenalectomy. Surg Laparosc Endosc Percutan Tech 2019; 29: 49-52.

10. Carvalho JA, Nunes PT, Antunes H, et al. Transumbilical laparoendoscopic single-site adrenalectomy: a feasible and safe alternative to standard laparoscopy. Arch Ital Urol Androl 2019; 91: 1-4.

11. Chen W, Xu ZB, Xu L, et al. Comparison of cosmetic effect and pain reduction outcomes of modified mini-laparoscopy versus laparoendoscopic single-site surgery for adrenalectomy. J Laparoendosc Adv Surg Tech A 2019; 29: 1544-8.

12. Hasegawa M, Miyajima A, Jinzaki $M$, et al. Visceral fat is correlated with prolonged operative time in laparoendoscopic single-site adrenalectomy and laparoscopic adrenalectomy. Urology 2013; 82: 1312-8.

13. Hirasawa Y, Miyajima A, Hattori S, et al. Laparoendoscopic single-site adrenalectomy versus conventional laparoscopic adrenalectomy: a comparison of surgical outcomes and an analysis of a single surgeon's learning curve. Surg Endosc 2014; 28 : 2911-9.

14. Hora M, Urge T, Stransky P, et al. Laparoendoscopic single-site surgery adrenalectomy - own experience and matched case-control study with standard laparoscopic adrenalectomy. Videosurgery Miniinv 2014; 9: 596-602.

15. Inoue S, Ikeda K, Kobayashi K, et al. Patient-reported satisfaction and cosmesis outcomes following laparoscopic adrenalectomy: laparoendoscopic single-site adrenalectomy vs. conventional laparoscopic adrenalectomy. Can Urol Assoc J 2014; 8: E20-5.

16. Ishida M, Miyajima A, Takeda T, et al. Technical difficulties of transumbilical laparoendoscopic single-site adrenalectomy: comparison with conventional laparoscopic adrenalectomy. World J Urol 2013; 31: 199-203.

17. Jeong BC, Park YH, Han DH, et al. Laparoendoscopic single-site and conventional laparoscopic adrenalectomy: a matched case-control study. J Endourol 2009; 23: 1957-60.

18. Kwak HN, Kim JH, Yun JS, et al. Conventional laparoscopic adrenalectomy versus laparoscopic adrenalectomy through mono port. Surg Laparosc Endosc Percutan Tech 2011; 21: 439-42.

19. Lin VC, Tsai YC, Chung SD, et al. A comparative study of multiport versus laparoendoscopic single-site adrenalectomy for benign adrenal tumors. Surg Endosc 2012; 26: 1135-9.

20. Shi TP, Zhang X, Ma X, et al. Laparoendoscopic single-site retroperitoneoscopic adrenalectomy: a matched-pair comparison with the gold standard. Surg Endosc 2011; 25: 2117-24.

21. Tunca F, Senyurek YG, Terzioglu T, et al. Single-incision laparoscopic adrenalectomy. Surg Endosc 2012; 26: 36-40.
22. Vidal O, Astudillo E, Valentini M, et al. Single-incision transperitoneal laparoscopic left adrenalectomy. World J Surg 2012; 36 : 1395-9.

23. Walz MK, Groeben H, Alesina PF. Single-access retroperitoneoscopic adrenalectomy (SARA) versus conventional retroperitoneoscopic adrenalectomy (CORA): a case-control study. World J Surg 2010; 34: 1386-90.

24. Wang L, Liu B, Wu Z, et al. Comparison of single-surgeon series of transperitoneal laparoendoscopic single-site surgery and standard laparoscopic adrenalectomy. Urology 2012; 79: 57783.

25. Wang Y, He Y, Li BS, et al. Laparoendoscopic single-site retroperitoneoscopic adrenalectomy versus conventional retroperitoneoscopic adrenalectomy in obese patients. J Endourol 2016; 30: 306-11.

26. Wen SC, Yeh HC, Wu WJ, et al. Laparoendoscopic single-site retroperitoneoscopic adrenalectomy versus conventional retroperitoneoscopic adrenalectomy: initial experience by the same laparoscopic surgeon. Urol Int 2013; 91: 297-303.

27. Kozlowski T, Choromanska B, Wojskowicz P, et al. Laparoscopic adrenalectomy: lateral transperitoneal versus posterior retroperitoneal approach - prospective randomized trial. Videosurgery Miniinv 2019; 14: 160-9.

28. Inoue S, Hayashi T, Hieda K, et al. Longitudinal analysis of laparoendoscopic single-site adrenalectomy and conventional laparoscopic adrenalectomy regarding patient-reported satisfaction and cosmesis outcomes. Asian J Surg 2019; 42: 514-9.

29. Lucas SM, Baber J, Sundaram CP. Determination of patient concerns in choosing surgery and preference for laparoendoscopic single-site surgery and assessment of satisfaction with postoperative cosmesis. J Endourol 2012; 26: 585-91.

30. Agcaoglu O, Karahan SN, Tufekci T, et al. Single-incision robotic adrenalectomy (SIRA): the future of adrenal surgery? Gland Surg 2020; 9: 853-8.

31. Park JH, Walz MK, Kang SW, et al. Robot-assisted posterior retroperitoneoscopic adrenalectomy: single port access. J Korean Surg Soc 2011; 81 Suppl 1: S21-4.

Received: 6.07.2021, accepted: 3.08.2021 